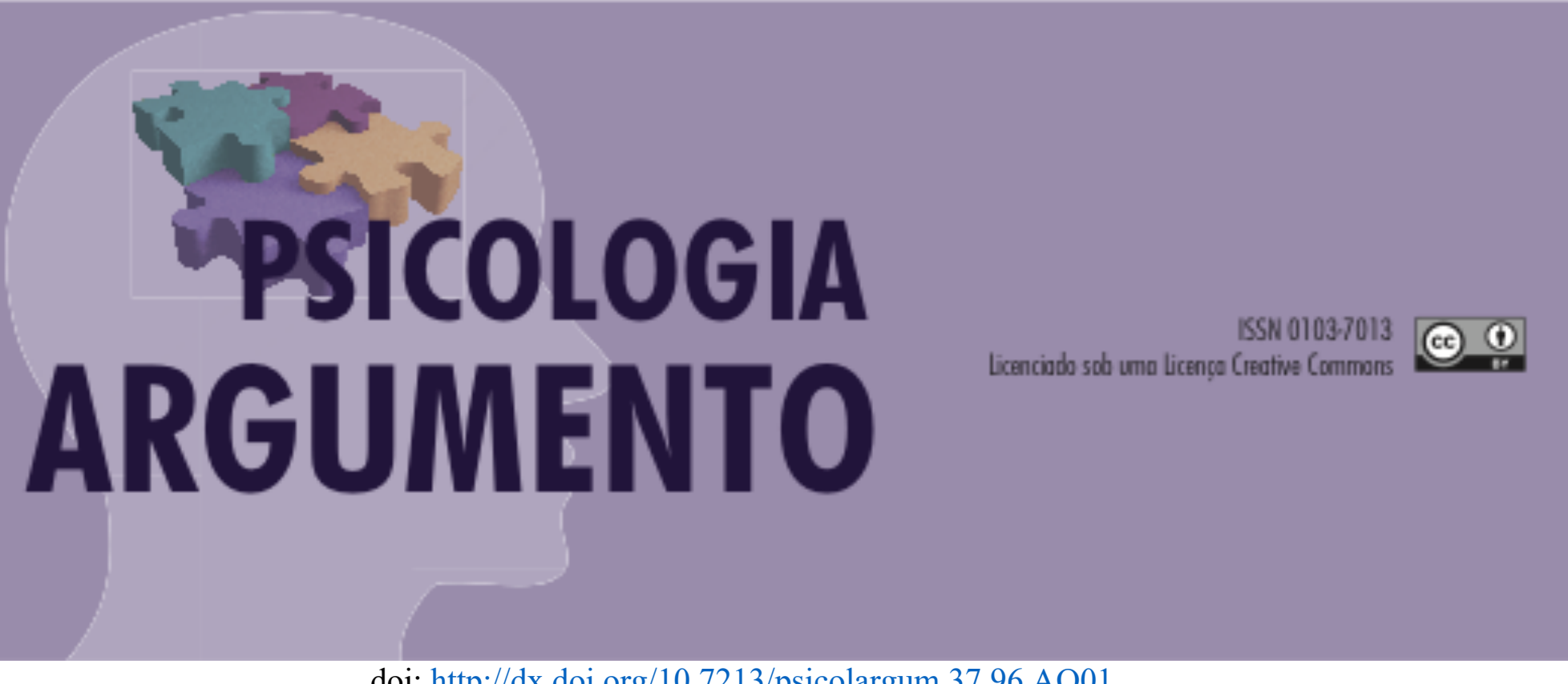

doi: http://dx.doi.org/10.7213/psicolargum.37.96.AO01

\title{
Valores cristão-católicos nas representações sociais de psicólogas(os) sobre a sua atuação profissional
}

Christian-Catholic values in the social representations of psychologists about their professional actuacion

Valores cristiano-católicos en las representaciones sociales de los psicólogos sobre su actuaciones profesionales

Carlos Vinicius Gomes Melo

http://orcid.org/0000-0002-3754-8905

Pós-doutorado do Instituto de Psicologia da Universidade São Paulo (USP)

São Paulo, SP. Email: cvgmelo@usp.br

Yuri Sá Oliveira Sousa

http://orcid.org/0000-0002-8713-5543

Professor Adjuneto do Instituto de Psicologia da Universidade Federal da Bahia (UFBA) Salvador, BA. Email: yurisousas@gmail.com

Alessandro de Oliveira dos Santos

http://orcid.org/0000-0002-5261-0332

Professor Livre-docente do Instituto de Psicologia da Universidade de São Paulo (USP)

São Paulo, SP. Email: alos@usp.br 


\section{Resumo}

Como se sabe, boa parte da institucionalização da história da psicologia no Brasil ocorre a partir da filosofia escolástica e de forte influência política cristão-católica. A partir de tal registro, adotou-se a hipótese de que as representações sociais das(os) psicólogas(os) sobre sua profissão estão associadas a valores cristão-católicos. Baseada na Teoria das Representações Sociais, a presente pesquisa identificou os elementos dessa história da psicologia advinda da referida corrente religiosa por meio de evocações livres de 657 participantes de três Estados brasileiros de diferentes regiões do país. A hipótese foi testada em duas etapas: primeira, análise lexicográfica das evocações livres, com o uso do software Iramuteq, pela aplicação do processamento baseado na Classificação Hierárquica Descendente; segunda, análise de conteúdo das representações classificadas pelo software. Constatados os valores da ética social cristã e da teologia da libertação no campo semântico das(os) psicólogas(os) sobre a sua atuação, pode-se caracterizar a influência do catolicismo no processo civilizatório do país, refletida mais especificamente na institucionalização da psicologia brasileira.

Palavras-chave: História da psicologia; Psicologia Brasileira; Psicólogos; Catolicismo; Representações sociais.

\section{Abstract}

As is well known, much of the institutionalization of the history of psychology in Brazil comes from scholastic philosophy and strong Christian-Catholic political influence. From this record, it was adopted the hypothesis that the social representations of psychologists about their profession are associated with Christian-Catholic values. Based on the Theory of Social Representations, the present research identified the elements of this history of psychology coming from such religious current through free evocations of 657 participants from three Brazilian states from different regions of the country. The hypothesis was tested in two stages: first, lexicographic analysis of free evocations, using the Iramuteq software, by applying Descending Hierarchical Classification processing; second, content analysis of the representations classified by the software. Having verified the values of Christian social ethics and liberation theology in the semantic field of psychologists about their performance, one can characterize the influence of Catholicism in the civilizing process of the country, more specifically reflected in the institutionalization of Brazilian psychology.

Keywords: History of Psychology; Brazilian psychology; Psychologists; Catholicism; Social representations.

\section{Resumen}

Como es bien sabido, gran parte de la institucionalización de la historia de la psicología en Brasil proviene de la filosofía escolástica y la fuerte influencia politica cristiano-católica. A partir de este registro, se adoptó la hipótesis de que las representaciones sociales de los psicólogos sobre su profesión están asociadas con valores cristiano-católicos. Basado en la teoría de las representaciones sociales, la presente investigación identificó los elementos de esta historia de la psicología que provienen de esa corriente religiosa a través de evocaciones gratuitas de 657 participantes de tres estados brasileños de diferentes regiones del país. La hipótesis se probó en dos etapas: primero, análisis lexicográfico de evocaciones libres, utilizando el software Iramuteq, aplicando el proceso de Clasificación jerárquica descendente; segundo, análisis de contenido de las representaciones clasificadas por el software. Después de verificar los valores de la ética social cristiana y la teología de la liberación en el campo semántico de los psicólogos sobre su desempeño, se puede 
caracterizar la influencia del catolicismo en el proceso civilizador del país, reflejado más específicamente en la institucionalización de la psicología brasileña.

Palabras clave: Historia de la psicología; Psicología brasileña; Psicólogos Catolicismo; Representaciones sociales.

\section{Introdução}

A(o) psicóloga(o) é um papel social imbuído de significados culturais e históricos. Por isso, para investigar tal identidade profissional se utiliza a análise dos fenômenos simbólicos formados por linguagens que permitem dar sentido a ela mesma. Mediante as representações sociais de psicólogas(os) sobre sua própria profissão, a presente pesquisa objetivou identificar quais elementos da história da psicologia brasileira, advindos do pensamento católico, são constituintes da sua identidade e atuação.

A partir de um estudo de revisão sistemática, Mazer e Melo-Silva (2010) verificam que a identidade da(o) psicóloga(o) brasileira(o) é concebida enquanto uma construção de um conjunto integrado de fatores pessoais e de formação de cada profissional. Ela passa pela questão da escolha e expectativa em relação à psicologia como profissão, da formação acadêmica e dos significados e vivências particulares de ser psicóloga(o). As autoras também tecem considerações sobre a necessidade de contextualizar a atuação da psicologia na realidade brasileira, enfatizando o seu compromisso social.

Compreender esse fenômeno identitário através das(os) próprias(os) profissionais é necessário para contemplar seu caráter social, na medida em que "ser psicóloga(a)" assume diferentes significados. Ao mesmo tempo, esta é uma ocupação largamente inserida na prática cotidiana do país. Atualmente, somam-se 357.686 psicólogas(os) nas mais diversas frentes de atuação (Conselho Federal de Psicologia, 2019), as quais, segundo a Classificação Brasileira de Ocupações (Brasil, 2010), trabalham na áreas da educação, clínica, esporte, hospitalar, jurídica, social, trânsito, trabalho, neuropsicologia e até acupuntura.

Com base na teoria da sociologia da profissão, Pereira e Pereira Neto (2003) afirmam que a profissão é um conceito que remete a um tipo específico de trabalho especializado e teoricamente fundamentado. Pressupõe-se que se detém um 
conhecimento complexo reconhecido pela sociedade e pelo Estado. Além disso, os interesses profissionais devem ser organizados em associações que padronizem a conduta dos pares, em função de uma autorregulação, através da fiscalização diante de um código de ética. Os autores apontam que tais requisitos foram considerados importantes para que a profissão de psicóloga(o) conquistasse a autoridade e a autonomia de seus serviços, diante da sociedade, no mercado de trabalho. No entanto, a dimensão histórica dessa institucionalização também é uma categoria a ser observada.

A partir das narrativas historiográficas de Antunes (2005), Sanchi (2005) e de Jacó-Vilela e Rocha (2014), apresenta-se a institucionalização da psicologia no Brasil a partir das influências filosóficas e políticas cristão-católicas. Entretanto, primeiro, cabe situar o advento de tais raízes filosóficas na psicologia. Rosenfeld (2006) oferece um roteiro sobre as percepções do fenômeno psicológico que vão desde a Grécia Antiga, passando pela emergência do cristianismo primitivo e sua noção de pessoa até a decorrente sistematização metodológica bem desenvolvida sobre o espírito ou a alma no âmbito da filosofia escolástica.

Rosenfeld (2006) considera os anseios religiosos cristãos do período helênico romano como uma transição histórica peculiar entre a filosofia da Antiguidade grega e o entendimento acerca da alma na Idade Cristã, ou seja, na Idade Média. Segundo o autor, os primórdios da psicologia moderna remontam à Antiguidade Grega. Com alicerce nas representações mitológicas, imersos no metafisicismo, surgiam os primeiros pensamentos e teorias psicológicas como tentativa metodológica de explicar os fatos da natureza por meio da observação dos fenômenos. Não obstante o prestígio da filosofia grega, no início da era cristã vigorou uma filosofia religiosa. Era o cristianismo emergente que buscava conhecer os mistérios da alma através do próprio pensamento grego racional, o que abriu caminho para as virtudes da fé.

Segundo o autor, a primeira fase da filosofia medieval cristã é a patrística, representada por Sto. Agostinho (354-430), quando se começou a compreender a fé divina por um racionalismo metodológico. Entretanto, o auge da Escolástica, considerada um método de pensamento crítico de aprendizagem, tem como principal referência São Tomás de Aquino (1225-1274). A corrente filosófica da escolástica apresenta ricas análises de problemas lógicos, epistemológicos, ontológicos e, principalmente, éticos. É o início de uma concepção bem elaborada, bem como de uma 
cultura que valoriza a existência individual e interior, e da imortalidade da alma (Rosenfeld, 2006).

Dentro da própria Escolástica, os fundamentos do racionalismo realista são abalados pelo emergente empirismo. Uma tendência científica começa a surgir através do experimento e da observação da natureza, tomando o lugar da análise erudita da tradição escolástica cristã (Rosenfeld, 2006). A insubordinação da tradição teocrática e a descrença cética somadas ao nascente individualismo produziram reações que estabeleceram novas bases e sistemas de crenças. Por exemplo, a noção de "vontade" começa a sair da conotação da "fé" e passa a alimentar a de "livre-arbítrio", como contraponto à crença na onipotência divina e seu controle absoluto da existência (Figueiredo, 2008; Sanchi, 2005).

$\mathrm{Na}$ transição da regência dos dogmas tradicionais para as crenças ideológicas que norteiam a modernidade, o cristianismo primitivo e o medieval influenciaram algumas características do que viria ser a cultura ocidental moderna (Dumont, 1985). Destacam-se as noções de "individualidade" e "interioridade", mas, também, o "universalismo", componente central da noção de "amor universal".

Rosenfeld (2006) destaca que a emergência da modernidade e a paulatina eliminação do caráter teosófico foram decisivas para o pensamento psicológico científico moderno do séc. XIX. De fato, afirma-se que a história da psicologia como um projeto científico nasce com as obras de Wilhelm Wundt (1832-1926) e de William James (1842-1910), na perspectiva de diferenciar-se da compreensão metafísica (Abib, 2009). Na época, surgiram também algumas correntes divergentes do atomismo psicológico, por exemplo, a psicanálise de Sigmund Freud (1856-1939) e a escola gestáltica, cujo principal expoente é Max Wertheimer (1880-1943) (Rosenfeld, 2006). Entretanto, no Brasil, as raízes éticas e filosóficas cristão-católicas permanecem bem evidentes na institucionalização e desenvolvimento da psicologia até o final do séc. XX. Conforme demonstram Antunes (2005), Sanchi (2005) e Jacó-Vilela e Rocha (2014), a epistemologia psicológica desenvolvida no país reflete tal influência filosófica e de valores desde a sua origem, na colônia, até os anos de 1980. O que, por sua vez, construiu as bases da identidade e atuação da psicologia brasileira.

Antunes (2005) aponta que, antes da modernização do Brasil e dos movimentos de institucionalização da profissão, os alicerces do pensamento psicológico começaram a se estabelecer no período colonial, ainda sobre as bases da ética religiosa, de 
influência escolástica e jesuítica. As temáticas possuíam grande relação com as pautas posteriores desenvolvidas pela psicologia brasileira, tais como o autoconhecimento e a objetivação da experiência interior (Antunes, 2005; Sanchi, 2005).

Como assevera Sanchi (2005), tais noções psicológicas e de compreensão sobre o humano são elaboradas a partir de ideias escolásticas, agostinianas e tomistas, vinculadas à "interioridade" e à ética cristã do "cultivo de si" pelo desenvolvimento da fé. O "cultivo de si" existia sob um rigoroso exame de consciência, pautado em uma obediência absoluta. Acompanhado pelo pecado, o "si" desenvolvido era enquadrado em um sistema sacramental e canônico, juridicamente reforçado pelo ensino da teologia moral.

A rigidez institucional no Brasil ganha ainda mais vigor a partir do movimento católico de Contrarreforma. O protestantismo afirmava-se pela emergência de um sujeito detentor de uma consciência soberana e insubordinada em relação ao quadro institucional canônico. A partir do movimento da Reforma Protestante, passa-se a questionar a confissão, o purgatório, a indulgência, a sacralização do sofrimento, entre outros fundamentos necessários para a "salvação" segundo a doutrina tradicional católica (Sanchi, 2005).

O estudo documental de Jacó-Vilela e Rocha (2014) permite notar essa transição discursiva mais concretamente na psicologia brasileira. Os autores analisam como os intelectuais católicos brasileiros perceberam e enfrentaram a emergência da psicologia científica. Como fonte de pesquisa, utilizaram artigos dos anos de 1920 até 1960 da Revista "A Ordem", direcionada ao público intelectual da época, e criada com vistas a recuperar a hegemonia da Igreja Católica. $\mathrm{Na}$ análise da primeira década, a partir de 1920, eles observam que os textos consideravam a psicologia ameaçadora em virtude de seu caráter materialista e evolucionista. Os intelectuais da época ressaltavam o lado moral e religioso para afirmar uma psicologia tomista. Na década de 1930, verificam o questionamento pedagógico do plano educacional da época, materializado pelo movimento da Escola Nova, que pautava o ensino laico e gratuito. Diante disso, evidenciava-se que os intelectuais católicos passaram a considerar a ciência e as práticas psicológicas ferramentas indispensáveis ao seu projeto pedagógico cristão, desde que devidamente subordinadas ao seu ideal educativo canônico. Nas décadas de 1950 e 1960 foi observada uma transformação discursiva. Embora psicanálise não fosse o referencial preferido e ainda houvesse a crítica à análise materialista e associacionista 
freudiana, a presença dos temas voltados a ela fazia pensar sobre a relevância teórica das relações entre a psicologia e a religião católica do momento. Registra-se a convicção de que a psicanálise não era bem aceita e de que seu conhecimento deveria ser restrito àqueles que têm a instrução necessária para discernir o que é válido ou não em seus postulados (Jacó-Vilela \& Rocha, 2014).

A investigação permite compreender a transição discursiva do viés religioso para o da psicologia moderna. Diante da emergência da psicologia científica, viu-se a importância da criação dos cursos de psicologia nas universidades católicas como forma de manutenção de seu objetivo de educar as elites e, principalmente, cuidar das almas (Jacó-Vilela \& Rocha, 2014). Destaque-se o primeiro curso autônomo de psicologia do Brasil, criado em 1953, na Pontifícia Universidade Católica do Rio de Janeiro, quase uma década antes da regulamentação da profissão (Yamamoto, 2006; Esch \& JacóVilela, 2001). Não por acaso, na década de 1960, em consonância com a abertura cultural católica para o conhecimento científico da psicologia, ocorre a regulamentação da profissão na legislação brasileira.

Em torno das décadas de 1960 e 70, em diferentes partes do Brasil, reformularam-se programas de formação de padres que estavam inseridos no tecido social. Foi estabelecido um processo sistemático de análise e formação psicanalítica, que englobava a perspectiva coletiva e comunitária. Alguns mosteiros pelo Brasil tornaram-se emblemas no campo da relação com a psicologia. Por exemplo, o mosteiro carmelita, em Belo Horizonte, que, em 1972, fundou o Centro de Integração Psicoteológica (CIPT) para religiosos(as), que mesclava a formação pastoral à terapia analítica psicológica (Sanchi, 2005).

Segundo Sanchi (2005), a datar da década de 1970, surge a Teologia da Libertação e Ética Social Cristã. A renovação proporcionou o "cultivo de si" sob o viés subjetivista e construtivista. No cenário de ditaduras latino-americanas, discutia-se criticamente a moral decorrente da opressão e da injustiça.

A década de 1980 é caracterizada pela psicologia pastoral na América Latina. A tendência latino-americana volta-se para o sujeito social e para coletivos empobrecidos. Buscava-se levar os grupos minoritários à superação das alienações culturais, com o propósito de construir uma nova sociedade pela prática do "Amor" e da "Justiça Social" (Sanchi, 2005). 
Com base nos pressupostos históricos expostos por Jacó-Vilela \& Rocha (2014) Antunes (2005) e Sanchi (2005), adota-se, aqui, a hipótese de que as representações sociais das(os) psicólogas(os) sobre a sua própria profissão estão relacionadas aos valores cristão-católicos. Acrescenta-se que a hipótese também se sustenta a partir do entendimento da identidade da(o) psicóloga(o) brasileira(o) segundo Mazer e MeloSilva (2010). Como observam as autoras, as concepções dessa identidade definem-se pela escolha pessoal da profissão, pelos significados e vivência de cada profissional. Ou seja, essa identidade é entendida como fonte de experiências únicas, irredutíveis e indeterminadas, próprias a cada psicóloga(o). O culto à experiência única da lógica de entendimento pararreligiosa é remetido à matriz de pensamento psicológico romântico ou pós-romântico. Segundo definição de Figueiredo (2008), a matriz do pensamento romântico ou pós-romântico valoriza os atos e vivências do sujeito, com a preocupação de apreender a experiência concreta, que é considerada anterior às abstrações, universalizações e objetivações, tal como é concebida na matriz cientificista. A acepção da identidade profissional com raízes em tal matriz de pensamento psicológico ilustra a herança metafísica e parrareligiosa da psicologia brasileira, permitindo inferir, então, a constituição de sua identidade a partir de traços ou características religiosas.

O referencial teórico vinculado às representações auxilia na análise dos fenômenos das realidades sociais, culturais, históricas e simbólicas que permeiam os processos comunicacionais das(os) psicólogas(os), permitindo dar sentido aos fenômenos do campo representacional da sua identidade profissional. No que lhes diz respeito, as representações são conteúdos mentais de natureza simbólica, sistemas compartilhados de significados que validam fatos sociais. São consideradas classificações e divisões que organizam as apreensões do mundo social como categoria de percepção do real, e, por conseguinte, a base de onde se originam os conceitos e crenças (Chartier, 1999; Quintaneiro, 1995).

A definição de representações sociais refere-se ao processo de construção do pensamento social (Chaves \& Silva, 2011), a saber, um conjunto dinâmico de conceitos, teorias, proposições e explicações destinado a interpretar e organizar o real da vida cotidiana. Esse conjunto é portador de dimensões históricas e transformadoras, presentes através de símbolos linguísticos, aspectos culturais, cognitivos e valorativos. Representar, assim, é um ato de pensamento que recoloca algo até então não cognoscível como presente na consciência. Faz exprimir uma relação com o objeto que 
é apropriado no universo simbólico do sujeito, implicando um papel ativo na sua forma de pensar e interpretar a realidade (Moscovici, 2003).

A teoria das representações sociais possui dois eixos de construção, um simbólico e um social (Moscovici, 2003), o que faz com que as representações funcionem como um fenômeno mediador entre indivíduo e sociedade (Chaves \& Silva, 2011). Além da dimensão da informação e da atitude, tal teoria se constitui na dimensão do campo representacional. $\mathrm{Na}$ dimensão da informação, os indivíduos ou grupos caracterizam qualitativa e quantitativamente determinado objeto social; e na da atitude, orientam-se valorativamente (de forma positiva ou negativa) em relação ao objeto. Destaca-se a dimensão do campo representacional, uma vez que os elementos simbólicos são organizados hierarquicamente, com conteúdos que diferem entre si quanto ao grau de importância para determinados grupos ou culturas (Moscovici, 2012).

Ademais, as representações constroem-se pelos processos da objetivação e da ancoragem. A objetivação é o processo de transformar um conceito em uma imagem, ou seja, concretiza-se algo do plano abstrato por meio de certas características, que privilegiam determinadas informações do objeto em detrimento de outras. Já o processo de ancoragem configura a inserção do objeto em um sistema de pensamentos preexistentes, quer dizer, classificado linguisticamente e vinculado a outras categorias já conhecidas (Moscovici, 2003).

A relação dos processos de objetivação e ancoragem com o campo de representações torna-se significativa para o estudo. A análise dos conteúdos objetivados e organizados hierarquicamente em um campo representacional pressupõe uma análise da rede de relações de sentido que constitui esse campo, isto é, implica considerar o processo de ancoragem na construção social do objeto em tela. A identidade e a atuação profissional da psicóloga(o) surgem como categorias linguísticas que evocam sentidos preexistentes e que, quando operadas, constroem simbolicamente experiências e práticas sociais conforme as diferentes áreas de atuação e vertentes teóricas e epistemológicas.

As representações sociais são estruturadas em uma hierarquia interna, o Núcleo Central e os Sistemas Periféricos. No núcleo central, ou sistema central, está o sistema estruturante e fundamental da representação, o que determina o seu significado e organização. O núcleo representacional é determinado pela natureza do objeto representado, assim como pelo tipo de seleção que determinado grupo aplica a este objeto a partir de um sistema de valores e normatividade social. Por ser central, torna-se 
mais resistente às mudanças, requerendo mais tempo para se modificar. Funciona como uma unidade que preserva a memória coletiva e social, conservando sua história e ideologias. Por isso, pode ser entendido como o responsável pela preservação dos significados de determinada representação social. À sua volta estão outros elementos menos rígidos dos conteúdos, integrando o que se define como "sistema periférico". Os elementos periféricos atualizam os conteúdos das representações, oferecendo perspectivas mais individuais e contraditórias, que ajudam o sistema central a se "ancorar na realidade". Dependendo do contexto, são mais acessíveis, concretos e transmutáveis. Concretizam a ancoragem e dão representação à realidade ao permitir a formulação da representação em termos concretos, imediatamente compreensíveis e transmissíveis. O caráter flexível (periférico) e consensual (central) das representações faz com que esses sistemas se complementem. Por exemplo, em função do frequente diálogo com os elementos periféricos, o sistema central pode variar em diferentes amostras populacionais (Abric, 2000; Chaves \& Silva, 2011; Sá, 1996). Sá (1996) ainda aponta que a dialética entre os universos individuais de experiências, os processos de formação e caracterização de grupos, e os contextos socioculturais temporais criam uma dinâmica de transformação das representações que torna mais difícil fazer delas entidades absolutas e rígidas.

Uma vez que o objeto principal do estudo expressa-se na ideia de um núcleo central característico à profissão de psicóloga(o), diante da transmutabilidade e permanência das representações sociais, questiona-se como legitimar a pesquisa de modo que sejam abrangidos todos os aspectos investigados. Sejam aspectos de conteúdo, das relações, bem como da organização entre seus elementos e sistemas. Tal questão metodológica remete à preocupação quanto ao uso do método de coleta, do processamento e análise de dados. Justo e Camargo (2014), quanto a esse aspecto, afirmam que a abordagem estrutural das representações sociais pode ser realizada mediante a técnica de evocação livre e submetida à análise lexicométrica, sistematizada pelos softwares Alceste e/ou Iramuteq.

\section{Método}

No que se refere à proposta de investigação exploratória e descritiva, as variáveis investigadas são as representações operacionalizadas a partir da identificação 
de universos lexicais que estruturam as respostas das evocações, e sua relação com a corrente religiosa. A pesquisa também testou a relação entre os campos lexicais identificados e a religiosidade/espiritualidade das(os) participantes, a sua abordagem teórica, o período etário, estado de residência, gênero e raça/cor.

\section{Participantes}

Participaram da pesquisa 657 psicólogas(os) residentes em três Estados de diferentes regiões do Brasil, a saber: Amazonas (9,58\%), Bahia (39,11\%) e São Paulo $(51,29 \%)$.

A proposta era a participação de profissionais oriundas(os) do Estado com maior volume de profissionais de psicologia em três regiões do país com particularidades culturais e linguísticas distintas. A escolha das(os) profissionais do Amazonas deve-se ao fato de ser esta a Unidade Federativa (UF) da Região Norte com mais psicólogas(os), sendo 3.345 ativos no CRP $20^{\circ}$ Região (CFP, 2015). A Bahia, da mesma forma, é o Estado com o maior número de profissionais do Nordeste, com 9.124 registrados(as) no CRP $3^{\mathrm{a}}$ Região (CFP, 2015). Já São Paulo é a UF com o maior número de profissionais de psicologia da Região Sudeste, somando um total de 86.058 ativos no CRP 6 a Região (CFP, 2015).

A média de idade das(os) participantes foi de 37,9 anos ( $\mathrm{DP}=10,28)$, sendo que a maioria possui entre 30 e 34 anos. Na distribuição por gênero, há uma proporção majoritariamente feminina $(79,6 \%)$. Os que se definem pelo gênero masculino são 19,9\% (N=131) e pelo gênero não binário são 0,5\% (N=03). Quanto aos dados étnicoraciais, apesar de a categoria branca ser a mais prevalente $(46,6 \%)$, quando agrupadas as categorias parda (33\%) e preta (18\%), as(os) participantes "negras(os)" passam a representar 51\% (N=335) do total. As(os) participantes amarelas(os) constituem 2,3\% $(\mathrm{N}=15)$ e a participação indígena é de $0,2 \%(\mathrm{~N}=01)$.

As(os) adeptas(os) das religiões de "matriz judaico-cristã" são as(os) mais prevalentes $(49,3 \% ; \mathrm{N}=324)$. Dentro dessa matriz, destaca-se o catolicismo, com $26 \%$ $(\mathrm{N}=171)$ do total de participantes, depois as religiões evangélicas protestantes ou congregacionistas $(11,4 \% ; \mathrm{N}=75)$, a espírita kardecista $(10,5 \%$; $\mathrm{N}=69)$, as(os) variantes gnósticas(os) $(1,1 \% ; \mathrm{N}=07)$ e a religião judaica $(0,3 \% ; \mathrm{N}=03)$. As adeptas(os) das religiões de matriz africana $(5,3 \% ; N=35)$ dividem-se entre a umbanda $(2,9 \% ; \mathrm{N}=19) \mathrm{e}$ o candomblé $(2,4 \% ; \mathrm{N}=16)$. As de matriz oriental $(2 \% ; N=13)$ pertencem ao budismo 
$(1,2 \% ; \mathrm{N}=08)$, à seicho-no-ie $(0,5 \% ; \mathrm{N}=03)$, ao islamismo $(0,2 \% ; \mathrm{N}=01)$ e à tradicional chinesa $(0,2 \% ; \mathrm{N}=01)$. Há ainda as(os) profissionais que definiram suas crenças sem matrizes religiosas específicas $(30,3 \% ; N=199)$, as(os) que não se definiram religiosamente/espiritualmente $(12,9 \% ; \mathrm{N}=85)$, as(os) espiritualistas $(9,6 \% ; \mathrm{N}=63)$ e as(os) agnósticas(os) (7,8\%; N=51). As(os) que não têm religião definiram-se como ateias/ateus $(9,4 \% ; \mathrm{N}=62)$. Finalmente, $3,7 \%(\mathrm{~N}=24)$ assinalaram o quesito "outros".

Relativamente à adoção de referencial teórico, 5,9\% (N=39) das(os) respondentes assinalaram não adotar um específico. No entanto, 94,1\% ( $\mathrm{N}=618)$ assumiram uma ou mais abordagens, considerando-se, também, que havia a possibilidade de sinalizar mais de um item. A maior parte, 58,4\% ( $\mathrm{N}=384)$, segue referenciais teóricos do pensamento psicológico de matriz "Romântica ou pósromântica"; e 20,7\% (N=136) segue a "Cientificista". As(os) que adotam o Ecletismo, são $10,8 \%(\mathrm{~N}=71)$. O ecletismo representa as(os) que se sentem mais confortáveis em adotar referenciais teóricos de ambas as matrizes de pensamento psicológico. As(os) que se alinham à matriz romântica ou pós-romântica aplicam a psicanálise, a psicodinâmica ou abordagens de base analítica (39\%; N=256), sócio-histórica $(25 \%$; $\mathrm{N}=164)$, humanista ou existencial $(18,4 \% ; \mathrm{N}=121)$, histórico-cultural $(14,3 \% ; \mathrm{N}=94)$, construtivista $(4,7 \% ; \mathrm{N}=31)$, ligada à gestalt $(4,6 \% ; \mathrm{N}=30)$, interpessoal $(2,1 \% ; \mathrm{N}=14) \mathrm{e}$ transpessoal $(1,8 \% ; \mathrm{N}=12)$. As(os) que adotam a matriz cientificista são as(os) que assinalaram as abordagens comportamentalista $(21,9 \% ; \mathrm{N}=144)$, cognitivista $(21,9$; $\mathrm{N}=144)$ ou evolucionista $(1,1 \% ; \mathrm{N}=07)$. Houve $12,2 \% \quad(\mathrm{~N}=80)$ que assinalaram "outros".

\section{Instrumento e procedimentos de coleta}

O instrumento utilizado foi um questionário composto por questões fechadas (e.g., variáveis sociodemográficas) e abertas (e.g., evocações livres). Com o objetivo de caracterizar o perfil sociodemográfico das(os) participantes, foram incluídas perguntas sobre idade, local de residência, gênero, a cor/raça, religiosidade/espiritualidade, grau de religiosidade e referencial teórico adotado. Visando identificar conteúdos de representações a respeito da atuação e da identidade profissional do(a) psicólogo(a), foram incluídas atividades de evocações livres.

Segundo Wolter e Wachelke (2013), a técnica de associação verbal, também denominada de Técnica de Associação Livre de Palavras (TALP), ou de evocações 
livres, é muito popular nos estudos sobre as representações e crenças. Ela consiste em pedir aos respondentes que escrevam palavras ou expressões que lhes venham espontaneamente à cabeça quando se deparam com determinado termo indutor, que geralmente é o fenômeno do objeto da representação em estudo. Nesta pesquisa, solicitou-se às(aos) respondentes que escrevessem até cinco palavras em cada atividade de evocação livre, realizada a partir dos seguintes termos indutores: "Atuação do(a) psicólogo(a)" e "Identidade do(a) psicólogo(a)". Aplicou-se o recurso de randomização na sequência de apresentação dos indutores. Ou seja, aleatoriamente, metade das(os) participantes tiveram acesso a um dos dois indutores e, em seguida, ao outro.

No intervalo de um ano, de 03 de agosto de 2017 à 31 de julho de 2018, os dados foram coletados mediante websurvey, com o questionário hospedado na plataforma online SurveyMonkey. As(os) profissionais acessaram e responderam por desktop, tablet ou celular conectado à internet. O procedimento de divulgação do questionário ocorreu por meio do acionamento de entidades de psicologia do Amazonas, da Bahia e de São Paulo, através das quais o link de acesso ao questionário circulou por lista de emails das(os) profissionais cadastradas(os).

Para tanto, foi elaborado um Termo de Consentimento Livre e Esclarecido (TCLE), de acordo com a Resolução no 466/2012 do Conselho Nacional de Saúde. O projeto da pesquisa foi submetido, via Plataforma Brasil, ao Comitê de Ética em Pesquisa com Seres Humanos e aprovado para execução, sob o número de registro CAAE 62444316.3.0000.5561.

\section{Procedimentos de análise}

Para examinar os conteúdos das evocações livres, realizou-se uma análise lexical, auxiliada pelo software Iramuteq, com base no método da Classificação Hierárquica Descendente (CHD). A análise lexical é uma abordagem metodológica fundamentada na estatística textual, ou lexicometria, que permite reorganizar a estrutura de um texto ou conjunto de textos com o objetivo de realizar observações baseadas em probabilidade a respeito da distribuição do seu vocabulário (Leblanc, 2015). O Iramuteq é um software gratuito, baseado no ambiente estatístico $\mathrm{R}$, que viabiliza a operacionalização de diferentes técnicas de análise lexical (e.g., estatísticas textuais clássicas, análise de especificidades, classificação hierárquica descendente, análise 
fatorial por correspondência, análise de similitude, análise prototípica de evocações e nuvem de palavras) (Camargo \& Justo, 2013, 2018; Ratinaud, 2014).

No presente estudo, os conteúdos evocados pelas(os) participantes em cada um dos contextos de resposta (i.e., atuação e identidade) constituíram segmentos de texto e, em seguida, foram submetidos a um tratamento lexical baseado na Classificação Hierárquica Descendente (CHD). A CHD é uma técnica de análise de agrupamentos (clusters) que realiza sucessivas partições no corpus em função da coocorrência de formas linguísticas em segmentos de texto. Esse método permite reconstituir classes lexicais homogêneas em função do vocabulário utilizado e, assim, identificar campos semânticos específicos (Nascimento \& Menandro, 2006). Nessa direção, entende-se que as classes lexicais indicam temas, representações e conceitos que são compartilhados e estruturam os conteúdos linguísticos analisados (Sousa, 2017).

Após a identificação das classes lexicais, o Iramuteq realiza testes de quiquadrado $\left(\chi^{2}\right)$ no sentido de verificar tendências na distribuição das formas linguísticas do corpus nas classes lexicais. Isso permite construir um dendrograma que representa as classes e as formas linguísticas mais associadas a cada uma delas. Além disso, a CHD pode ser utilizada para identificar relações entre as características lexicais dos enunciados e as posições sociais que ocupam os enunciadores (Reinert, 1987). Para tanto, é especialmente relevante incluir variáveis categóricas no tratamento dos dados com a finalidade de verificar a existência de associações entre as condições de produção do texto (e.g., características sociodemográficas) e as classes lexicais resultantes da CHD. Essas associações também são avaliadas mediante testes de qui-quadrado. Na presente pesquisa, foram testadas as seguintes variáveis: contexto de resposta (i.e., termo indutor sobre atuação ou identidade profissional), faixa etária, Estado de residência, gênero, raça/cor e religião. As associações significativas $(p<0,01)$ entre classes lexicais e as variáveis categóricas serão indicadas no texto, que equivale a $\chi^{2}<6,63$. Os dados coligidos por meio das etapas de coleta e processamento delinearam um quadro de informações que permitiu compreender e sistematizar aspectos da atuação e identidade das(os) psicólogas(os) brasileiras(os) representadas(os) por elas(eles). 


\section{Resultados}

Na descrição do Corpus, constam 657 textos, com 1.317 segmentos de texto, 7.292 ocorrências e 2.083 formas, que foram submetidos à Classificação Hierárquica Descendente, pelo Método Reinert. Como resultado da análise, foram classificados $87,47 \%$ (1.672), em 04 classes.

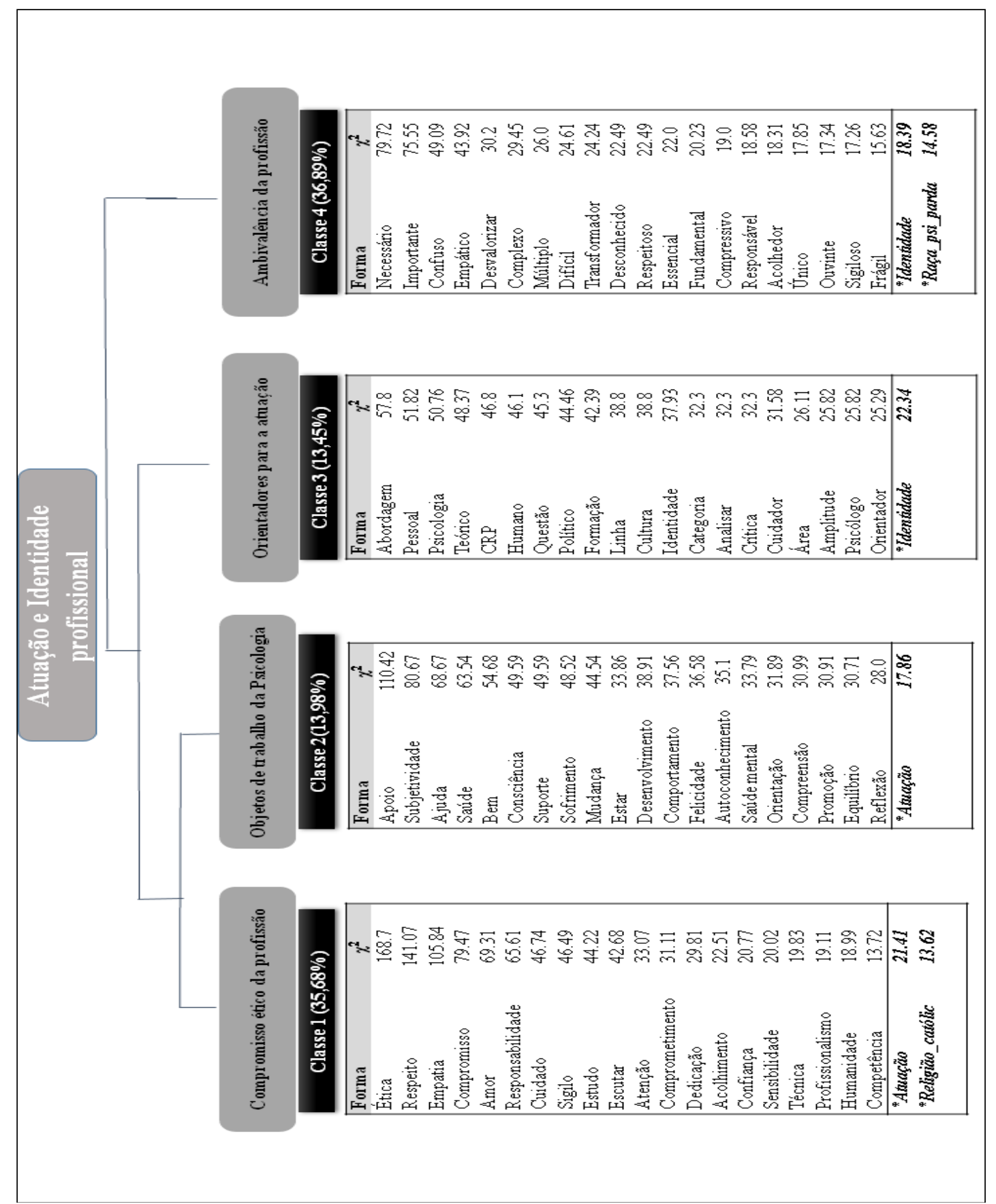

Figura 1. Dendrograma de classes e formas lexicais características encontradas ao final da CHD aplicada às evocações sobre Atuação e Identidade Profissional. Fonte de dados da pesquisa. 
Como se nota a partir do dendrograma da Figura 1, o processamento classificou o material a partir de um primeiro eixo que comporta as Classes 01 e 02 ; o segundo eixo amplia o primeiro com a Classe 03; e o terceiro eixo, que se diferencia das três primeiras classes, leva à Classe 04. A Classe 01 contém 35,68\% (411) dos conjuntos de evocações, que são tratados como ST. A Classe 02 tem 13,98\% (161) dos conjuntos de evocações. A Classe 03, 13,45\% (155). A Classe 04, 36,89\% (425).

Com base no qui-quadrado $\left(\chi^{2}\right)$, a ordem de significância das palavras demonstra que a Classe 01 é relativa ao Compromisso Social e Ético das(os) profissionais e concentra grande parte dos conjuntos de evocações $(35,68 \%)$. Os termos destacam o compromisso com os Valores Éticos Generalistas (Ética, Respeito, Empatia, Compromisso, Amor, Responsabilidade, Cuidado, Dedicação, Acolhimento, Confiança e Humanidade); bem como com Valores Éticos da Profissão (Sigilo, Atenção, Escutar, Técnica, Estudo, Competência e Atuação).

A Classe 01 está associada à variável *Atuação $\left(\chi^{2}=21,41\right)$, que se refere a atribuições para o evocativo "Atuação da/o psicóloga(o)". Tal associação é reforçada quando aplicado o recurso de Anti-perfil a cada classe, pois os termos evocados para "Identidade da/o psicóloga/o" estão sub-representados na Classe 01. Observa-se a dissociação significante pelo qui-quadrado negativo em *Identidade $\left(\chi^{2}=-21,41\right)$. Na Classe 01, também é evidenciada a associação com a *Religião_católic $\left(\chi^{2}=13,62\right)$, ou seja, com profissionais adeptas(os) da religião católica.

A Classe 02, a mais próxima lexicalmente da Classe 01, está relacionada aos Objetos de Estudo e Trabalho da Psicologia (Reflexão, Compreensão, Orientação, Promoção, Subjetividade, Saúde, Consciência, Sofrimento, Mudança, Desenvolvimento, Comportamento, Felicidade, Autoconhecimento, Saúde Mental, Equilíbrio, Apoio, [Bem]-[Estar], Suporte, Alívio). Nota-se novamente a associação com a *Atuação ( $\chi^{2}=$ $17,86)$, bem como a dissociação forte com a *Identidade $\left(\chi^{2}=-17,75\right)$.

Pertencente a um subeixo diferente das Classes 01 e 02, mas com uma proximidade intermediária, a Classe 03 resulta de noções que poderiam ser definidas como Orientadoras para a(o) psicóloga(o) (Abordagem , Psicologia, Teórico, CRP, Política, Formação, Linha, Cultura, Identidade, Categoria, Crítica, Área, Amplitude, Psicólogo, Orientador). Está associada aos termos evocados para a *Identidade $\left(\chi^{2}=\right.$ $22,34)$ e distante dos evocados para a *Atuação $\left(\chi^{2}=-22,34\right)$. 
A Classe 04, em um eixo separado, concentra as noções relativas às ambivalências da profissão (Complexo, Múltiplo, Amplo), que são definidas por pontos negativos (Confuso, Desvalor, Difícil, Desconhecido, Frágil) e por pontos positivos (Necessidade, Importante, Empático, Respeitoso, Essencial, Fundamental, Compreensivo, Responsável). Além disso, há imagens que inferem uma identidade da profissão (Responsável, Acolhedora, Única, Ouvinte e Sigiloso). Nota-se que tais ideias estão associadas a *Identidade $\left(\chi^{2}=18,39\right)$ e a *Raça_Psi_Parda $\left(\chi^{2}=14,58\right)$, referida a profissionais autodefinidas(os) pela raça/cor parda. Por outro lado, dissociada de *Atuação $\left(\chi^{2}=-18,39\right)$.

\section{Discussão}

Conforme os dados processados no software, as(os) psicólogas(os) demonstram representações sobre a sua profissão associadas a termos que reportam à sua história de herança cristão-católica, bem como a evocações descritas pelas adeptas(os) do catolicismo. Tais valores associam-se somente às evocações para a atuação profissional e não à identidade. Contudo, em razão da atuação profissional surgir como o núcleo central da profissão, pode-se afirmar que a análise lexical realizada corrobora a hipótese em questão neste estudo. A proximidade léxico-temática atribui as Classes 01 e 02 à atuação profissional, ao retratar o compromisso ético da psicologia (Classe 01) e os seus objetos de estudo e trabalho (Classe 02).

As evocações da Classe 01 são analisadas como os conteúdos do núcleo central das representações sobre a profissão. Elas remetem a valores éticos gerais e específicos da profisssão que estão alinhados às normas apresentadas no próprio Código de Ética Profisssional do Psicólogo (Resolução no 10/2005). O documento norteador da prática profissional estabelece padrões técnicos para a relação das(os) psicólogas(os) com seus pares e com a sociedade, por meio da reflexão sobre a responsabilidade ética pessoal e coletiva. Dos sete (07) princípios fundamentais, os (03) três primeiros afirmam que:

I. O psicólogo baseará o seu trabalho no respeito e na promoção da liberdade, da dignidade, da igualdade e da integridade do ser humano, apoiado nos valores que embasam a Declaração Universal dos Direitos Humanos. II. O psicólogo trabalhará visando promover a saúde e a qualidade de vida das pessoas e das coletividades e contribuirá para a eliminação de quaisquer formas de 
negligência, discriminação, exploração, violência, crueldade e opressão. III. O psicólogo atuará com responsabilidade social, analisando crítica e historicamente a realidade política, econômica, social e cultural (Resolução $n^{0}$ 010/2005, p.7).

Os valores "sobrerrepresentados" na Classe 01 são congruentes com o que é observado concretamente no Código de Ética Profissional que é imbuído no compromisso e responsabilidade com a sociedade. Como evidenciou a lexicografia, as(os) psicólogas(os) associam o centro de significados sobre a profissão a essa atuação comprometida socialmente e não a um modelo ou protótipo identitário profissional. Essa imagem central relaciona-se com o que é apontado por Mazer e Melo-Silva (2010), as quais constatam que a concepção identitária da(o) psicóloga(o) brasileira é relativizada pelas experiências de cada profissional, entendidas enquanto uma construção e estritamente contextualizadas segundo sua atuação, enfatizando-se o compromisso social.

A Classe 02 manifesta-se como a primeira periferia das representações, pois carrega os elementos mais intimamente relacionados ao núcleo central. Apresenta termos também vinculados à Atuação e estampa como são vistos os objetos de trabalho da psicologia.

Ambas as classes (Classes 01 e 02) compõem o eixo central (núcleo central e primeira periferia) da crença das(os) participantes, significativamente associada à atuação profissional, reproduzindo conteúdos mais preservados da história da psicologia brasileira e de suas ideologias. A centralidade nuclear dos valores éticos, associada aos termos usados pelas(os) profissionais adeptas(os) do catolicismo, resgata a história da psicologia fundada segundo epistemologias de tradição filosóficas e culturais cristãocatólicas. Além disso, conforme a análise de conteúdo, tal classe remete às noções éticas cristãs de amor universal, do sigilo no âmbito da confissão, do sofrimento, de justiça e ética social e da função salvacionista pastoral-teológico-libertária da(o) psicóloga(o) frente às formas de desigualdade e opressão, como apontam Jacó-Vilela (2014), Sanchi (2005) e Antunes (2005).

Na segunda camada da periferia, está a Classe 03 que, por seu turno, apresenta noções orientadoras das(os) profissionais da psicologia que passam por múltiplas referências. Desde abordagens psicológicas teóricas às pessoais, políticas, formativas, 
culturais, identitárias, crítica, etc. O perfil orientador da profissão, evidenciado na classe, concilia-se com o perfil da matriz de pensamento psicológico romântico e pósromântico, cujos referenciais teóricos, não por acaso, são os mais adotados pelas(os) respondentes da pesquisa.

Conforme Figueiredo (2008), acima referido, a matriz romântica ou pósromântica é atribuída a uma vertente com raízes na pararreligiosidade e na metafísica, o que indica uma influência filosófica religiosa. Desde que a psicologia brasileira constitui-se nesse contexto, ela opera com uma cultura profissional imersa em densas análises culturais, sociais e políticas. Ela assume posições de profundas reflexão e erudições críticas acerca de seu exercício e produção de conhecimento, com vertentes de atuação pouco abalizadas por evidências científicas, comparativamente às correntes psicológicas advindas de matrizes cientificistas.

Em função da sua matriz de pensamento psicológico predominante, por não ter um perfil de pensamento objetificado pela cientificidade, a identidade profissional da psicologia brasileira pode se manifestar em uma ideia de confusão, como se nota na Classe 04. Como identificado por Mazer e Melo-Silva (2010), na literatura da área, a identidade da(o) psicóloga(o) é concebida pela diversidade de métodos e práticas da Psicologia associados à singularidade das trajetórias pessoais de cada profissional, apresentando-se em constante construção, transformação e mudança. Tal multiplicidade, decorrente da matriz de pensamento, é ilustrada por Paredes-Rivera (2016) mediante o fato de que o campo da psicoterapia, por exemplo, conta com mais de 400 modalidades, em cuja maioria não há indicadores comprobatórios de que os procedimentos efetuam as mudanças que dizem realizar.

A Classe 04 está na qualidade de camada mais periférica, com os elementos mais transmutáveis das representações sobre a profissão. É a mais distante do núcleo representacional, mas com maior volume de conjunto de evocações. Associada à identidade $\mathrm{da}(\mathrm{o})$ psicóloga(o), nela se expressam as ambiguidades das(os) próprias(os) participantes relativas à profissão. Em uma das mãos, representa a sua extrema importância social, na outra, também a sua nebulosidade e falta de compreensão. A ambivalência identitária representada na Classe 04 também se revela nos termos evocados por profissionais pardas(os), ou seja, negras(os).

De acordo com os dados coletados em 2014, a proporção de psicólogas(os) negras(os) era de 16,5\% (DIEESE, 2016). Contudo, a partir de dados do Instituto 
Brasileiro de Geografia e Estatística (IBGE) de 2018, a Agência Brasil publicou que os negros correspondem a $50,3 \%$ da população de estudantes de ensino superior em instituições públicas brasileiras (Nitahara, 2019).

As(os) psicólogas(os) pretas e pardas(os) integram a psicologia trazendo consigo epistemologias e entendimentos contra-hegemônicos. A relação entre a ambivalência da profissão e a raça/cor parda das(os) profissionais pode estar relacionada, por um lado, à compreensão da importância dos recursos da psicologia para as relações étnico-raciais e para os efeitos psicossociais do racismo, mas, por outro, a uma incompatibilidade de saberes.

No jogo de poder entre os saberes, a colonialidade epistemológica que opera por reproduções de regimes rígidos do saber pode estar se refletindo na experiência vivida por essas(esses) profissionais negras(os), produzindo impacto na sua linguagem e visão de mundo (Assis, 2014). O autorreconhecimento identitário profissional está na linguagem e o atributo linguístico-identitário ambivalente evidenciado pode reportar uma confusão por incompatibilidades epistêmicas entre saberes hegemônicos e contrahegemônicos. Como ilustração, Dimenstein (2000) acusa que, embora atualmente a atuação das(os) psicólogas(os) esteja comprometida com o social, sua formação ainda se caracteriza por uma cultura profissional regida pelo viés individualista e universalista. Tal ideário reforça a noção de que os sofrimentos decorrentes do preconceito e discriminação étnico-racial são de ordem individual, devendo ser, então, superados por meio de elaborações e recursos do próprio indivíduo.

Como observado nas Classes 03 e 04, as características identitárias conferidas pelas(os) próprias psicológas(os) à profissão manifestam-se multirreferenciadas e até confusas. Elas podem ser observadas pelas múltiplas abordagens teóricas ou por orientações de outras ordens (pessoais, políticas, formativas, culturais, identitárias, críticas), assim como pela ambivalência entre a importância social e a má compreensão dessa identidade profissional. O que, por fim, reforça aquilo que evidenciaram Mazer e Melo-Silva (2010), a saber, que a psicologia é uma profissão em construção. Além disso, tal imprecisão identitária alocada na zona mais periférica das representações sociais sobre a profissão transmite o ponto de vista estrutural da teoria. Com base em Sá (1996), pode-se dizer que as camadas mais periféricas das imagens sobre a profissão vão oferecer as perspectivas mais contraditórias e transmutáveis. Contudo, também proporcionam as crenças mais concretas que auxiliarão o núcleo central dessa 
representação a se ancorar na realidade cotidiana das(os) próprias(os) psicólogas(os) bem como no cotidiano social brasileiro.

\section{Considerações finais}

O estudo constata que o núcleo central das representações sociais das(os) psicólogas(os) sobre a sua profissão associa-se à atuação e ao compromisso social, bem como à ética e valores da filosofia e epistemologia cristão-católica. O fenômeno concretiza-se mediante os conteúdos das crenças que remetem a noções cristãs de amor universal e empatia, de sigilo no âmbito da confissão, de sofrimento, de autoconhecimento, de justiça e ética social, bem como na postura libertária pastoral salvacionista. A hipótese testada também se confirma pela forte associação de tais representações aos termos evocados por profissionais adeptas(os) do catolicismo.

O poder do processo civilizatório cristão-católico no país e na história da psicologia pode ter determinado uma adesão maior das(os) psicólogas(os) às vertentes teóricas orientadas pela matriz de pensamento psicológico romântico ou pós-romântico em função da sua herança metafísica e pararreligiosa.

Nos sistemas mais periféricos das representações sociais está a noção de identidade profissional pulverizada por múltiplos referenciais da psicologia e por ambivalências e confusão compreensiva. A ambivalência na identidade profissional associa-se às(aos) participantes negras(os), especificamente, pardas(os). Tal ambiguidade pode se relacionar ao epistemicídio em virtude da colonialidade dos saberes hegemônicos da psicologia, impactando as(os) profissionais com suas concepções contra-hegemônicas de ser e existir de si e de outros.

A confirmação da hipótese estudada esboça, a partir de análises lexicais e de conteúdo, como a colonialidade cristão-católica cunhou o desenvolvimento da psicologia no Brasil. Constata-se que o pensamento católico da história da psicologia alcança nos dias de hoje as representações centrais das(os) psicólogas(os) sobre a sua profissão, em especial, a atuação profissional. 


\section{Agradecimentos}

O artigo é composto com resultados de pesquisa apoiada pela Fundação de Amparo a Pesquisa do Estado de São Paulo (FAPESP), Processo 2016/00577-4.

\section{Referências}

Abib, J. (2009). Epistemologia pluralizada e história da psicologia. Scientiae Studia, 7(2), pp. 195-208. https://doi.org/10.1590/S1678-31662009000200002.

Abric, J. C. (2000). A abordagem estrutural das representações sociais. In A. S. P. Moreira \& D. C. Oliveira (org.). Estudos interdisciplinares de representação social (2a. ed., pp. 27-38). Goiânia: AB.

Antunes, M. A. M. (2005). A psicologia no Brasil: leitura histórica sobre sua constituição. São Paulo: Unimarco Editora/Educ 4a. (Original publicado em 1998).

Assis, W. F. T. (2014). Do colonialismo à colonialidade: expropriação territorial na periferia do capitalismo. Caderno CRH, Salvador, v. 27, n. 72, pp. 613-627.

Brasil, Ministério do Trabalho e Emprego (2010). Classificação Brasileira de Ocupações: CBO-2010 - $3^{\mathrm{a}}$ ed. Brasília: MTE, SPPE.

Camargo, B. V., \& Justo, A. M. (2013). IRAMUTEQ: Um software gratuito para análise de dados textuais. Temas em Psicologia, 21(2), pp. 513-518.

Chartier, R. (1990). Introdução. Por uma sociologia das práticas culturais. In: Chartier. R. A história cultural entre práticas e representações. Col. Memória e Sociedade. Trad. Maria Manuela Galhado. Rio de Janeiro: Bertrand Brasil, pp. 13-28.

Chaves, A. M., \& Silva, P. L. (2011). Representações Sociais. In L. Camino, A. R. R. Torres, M. E. O. Lima, \& M. E. Pereira (Orgs.). Psicologia Social: Temas e Teorias (pp. 299-349). Brasília: Technopolitik.

Conselho Federal de Psicologia (2019). A Psicologia brasileira apresentada em números. Dado atualizado em 20 de novembro de 2019. Disponível em: http://www2.cfp.org.br/infografico/quantos-somos/

Conselho Federal de Psicologia (2015). A Psicologia brasileira apresentada em números. Dado atualizado em 12 de outubro de 2015. Disponível em: http://www2.cfp.org.br/infografico/quantos-somos/

Departamento Intersindical de Estatística e Estudos Socioeconômicos-DIEESE (2016). Levantamento de informações sobre a inserção dos psicólogos no mercado de trabalho brasileiro - Relatório final da análise de Dados. Contrato de Prestação de Serviços DIEESE - Conselho Federal de Psicologia.

Dimenstein, M. (2000). Cultura Profissional do Psicólogo e o ideário individualista: implicações para a prática no campo da assistência pública à saúde. Estudos de Psicologia, 5(1), 95-121.

Dumont, L. (1985) O individualismo: uma perspectiva antropológica da ideologia moderna. Rio de Janeiro: Rocco. 
Esch, C. F., \& Jacó-Vilela, A. M. (2001). A regulamentação da profissão e os currículos de formação psi. In A. M. Jacó-Vilela, A. C. Cerezzo, \& H. B. C. Rodrigues (Orgs.), ClioPsyché hoje: fazeres e dizeres psi na história do Brasil (pp. 17-24). Rio de Janeiro: Relume Dumará; FAPERJ.

Figueiredo, L. C. N. (2003). Psicologia, uma (nova) introdução: uma visão histórica da psicologia como ciência. $2^{\mathrm{a}}$ ed. São Paulo: EDUC.

Figueiredo, L. C. N. (2008). Matrizes do pensamento psicológico. 14.ed. Petrópolis: Vozes.

Jacó-Vilela, A. M., \& Rocha, L. F. D. da. (2014). Uma Perspectiva Católica da Psicologia no Brasil: Análise de Artigos da Revista "A Ordem". Psicologia em Pesquisa, 8(1), 115126. https://dx.doi.org/DOI: 10.5327/Z1982-1247201400010011

Justo, A. M. \& Camargo, B. V. (2014). Estudos qualitativos e o uso de softwares para análises lexicais. Caderno de artigos dos Anais do X SIAT \& II SERPRO. Caxias do Sul, RJ.

Leblanc, J.-M. (2015). Proposition de protocole pour l'analyse des données textuelles: Pour une démarche expérimentale en lexicométrie. Nouvelles perspectives en sciences sociales (NPSS), 11(1), 25-63.

Mazer, S. M., \& Melo-Silva, L. L.. (2010). Identidade profissional do Psicólogo: uma revisão da produção científica no Brasil. Psicologia: ciência e profissão, 30(2), 276-295. Recuperado em 19 de novembro de 2019, de http://pepsic.bvsalud.org/scielo. php?script=sci_arttext\&pid=S1414-98932010000200005\&lng=pt\&tlng=pt.

Moscovici, S. (2012). A psicanálise, sua imagem e seu público. Petrópolis: Vozes.

Moscovici, S. (2003). Representações sociais: investigações em psicologia social. Petrópolis: Vozes.

Nascimento, A. R. A., \& Menandro, P. R. M. (2006). Análise lexical e análise de conteúdo: uma proposta de utilização conjugada. Estudos e Pesquisas em Psicologia, 6(2), pp. 7288.

Nitahara, A. (2019, 13 de novembro). Pela primeira vez, negros são maioria no ensino superior público. Agência Brasil. Recuperado em http://agenciabrasil.ebc.com.br /geral/noticia/2019-11/pela-primeira-vez-negros-sao-maioria-no-ensino-superior publico

Paredes-Rivera, A. (2016). La urgencia de la evidencia en psicoterapia. Interacciones: Revista de Avances en Psicología, 2(1), 53-63. doi:10.24016/2016.v2n1.21

Quintaneiro, T. (1995). Émile Durkheim. In Quintaneiro, T., Barbosa M. L. e Oliveira, M. G. de. Um toque de clássicos: Durkheim, Marx e Weber. Belo Horizonte: Editora UFMG.

Ratinaud, P. (2014). IRAMUTEQ: Interface de R pour les Analyses Multidimensionnelles de Textes et de Questionnaires—0.7 alpha 2. Recuperado de http://www.iramuteq.org

Reinert, M. (1987). Classification Descendante Hierarchique et Analyse Lexicale par Contexte-Application au Corpus des Poesies D’A. Rimbaud. Bulletin de Méthodologie Sociologique, 13(1), 53-90.

Rosenfeld, A. (2006). O pensamento psicológico. $2^{\mathrm{a}}$ ed. São Paulo: Perspectiva.

Sanchi, P. (2005). A Igreja Católica no Brasil e a dimensão do "sujeito". In Duarte, L. F. D. \& Venancio, A. T. (orgs.). Psicologização no Brasil: atores e autores. Contra Capa Livraria. 
Sá, C. P. (1996). Núcleo Central das Representações Sociais. Petrópolis: Vozes.

Sousa, Y. S. O. (2017). Drogas e normalização: uma análise psicossocial desde a perspectiva das representações sociais (Tese de Doutorado). Universidade Federal de Pernambuco, Centro de Filosofia e Ciências Humanas, Pós-Graduação em Psicologia, Recife.

Wolter, R. P., \& Wachelke, J. F. R. (2013). Índices de distribuição de evocações: raridade, diversidade e comunidade de corpora de representações sociais. Revista de Psicologia: Teoria e Prática, 15,119-129.

Yamamoto, O. H. (2006). Graduação e pós-graduação em psicologia: relações possíveis. Revista Brasileira de Pós-Graduação, 3(6), 270-281. 